\title{
The effect of the controllability of auditory discriminative stimuli in the performance of go/no-go discriminations by pigeons
}

\author{
JAMES P. RODGERS \\ University of Colorado at Boulder, Boulder, Colorado 80309 \\ ARTHUR TOMIE \\ Rutgers-The State University, New Brunswick, New Jersey 08903 \\ and \\ DAVID R. THOMAS \\ University of Colorado at Boulder, Boulder, Colorado 80309
}

\begin{abstract}
Compared with their performance with localized (on-key) visual stimuli, pigeons are notoriously poor at performing go/no-go discriminations when keypecking for food in the presence of auditory discriminative stimuli. The difference might reflect the fact that an aversive visual onkey stimulus signaling nonreward can be escaped by looking away and not pecking, which contributes to the measure of good discriminative performance, while an auditory stimulus cannot be escaped. In Experiment 1, discriminative performance was significantly improved by providing pigeons with a response incompatible with keypecking by which they could escape a tone $\mathrm{S}+$ and a tone $\mathrm{S}-$. However, the pattern, frequency, and duration of escape responses were found to be insufficient to explain the improvement. In Experiment 2, it was found that the capacity to escape only S+ or only S- enhanced discriminative performance as much as the capacity to escape both. It is theorized that the Pavlovian relationship between the absence of the discriminative stimuli and the nonoccurrence of food might transfer to the instrumental relationships learned in a go/no-go discrimination. The possibility that intermittent stimuli command more attention than continuous stimuli is also considered.
\end{abstract}

In a number of unpublished investigations in our own laboratory and those of others, it has been observed that pigeons do not perform go/no-go discriminations well when the discriminative stimuli are auditory (tones), the reinforcer is access to grain, and the rewarded operant is keypecking. Powell (1973) reported poor discriminative performance, as indexed by the percent of total responses during S+ (the "discrimination ratio"), in a variable-interval extinction (VI-EXT) discrimination when the VI signal ( $\mathrm{S}+$ ) was silence and the EXT signal $(\mathrm{S}-$ ) was a $1,234-\mathrm{Hz} 90-\mathrm{dB}$ tone, relative to

This research is based on a thesis by the first author submitted to the faculty of the Graduate School of the University of Colorado in partial fulfillment of the requirements for the degree of Master of Arts. It was supported by NIH Research Grant HD-03486 and NSF Research Grant BNS-7801407 to the third author. Experiment 1 was reported by the first author at the May 1975 meetings of the Rocky Mountain Psychological Association at Salt Lake City. Utah. The authors wish to thank Elizabeth M. Lowell for her flawless assistance in the reduction and computerbased analysis of portions of the data and Thomas B. Moye and Robert J. Newlin for helpful comments on the manuscript. Requests for reprints should be addressed to James P. Rodgers or David R. Thomas at the Department of Psychology, University of Colorado at Boulder, Boulder, Colorado 80309. performance in a discrimination in which $\mathrm{S}+$ was a red keylight and $\mathrm{S}-$ was a white keylight. The source of the difference was higher keypecking rates when $\mathrm{S}-$ was a tone than when $\mathrm{S}-$ - was a keylight.

The finding that differences among treatment groups in discriminative performance in a go/no-go task is the product of differences in $\mathrm{S}$ - response rates rather than St response rates is common (Eck, Noel, \& Thomas, 1969; Eck \& Thomas, 1970) and may be explained by frustration theory. Amsel (1958) proposed that nonreward (EXT) in a situation in which reward has previously occurred elicits a primary aversive drive state which he called "frustration." In discriminations involving approach and avoidance, that is, successive go/no-go and simultaneous two-choice discriminations, $S+$ acquires the capacity to elicit approach and $\mathbf{S}$ - comes to elicit avoidance. Amsel (1962) subsequently refined his views when he asserted that "cues paired with frustrative nonreward acquire aversive properties; and ... the cessation of cues paired with frustrative nonreward serves to reinforce a new response" (p. 308). Amsel's suggestion has led to a body of research purporting to demonstrate that animals will acquire a "new" response to escape from an instrumental S- (Wagner, 1963). Perhaps the crucial difference between auditory and 
on-key visual discriminative stimuli is the fact that an on-key $\mathrm{S}$ - can be escaped, but only by behavior incompatible with keypecking (e.g., looking away), whereas an auditory $\mathrm{S}$ - cannot be escaped by any means.

Escape from $\mathrm{S}-$ has been reported for pigeons performing go/no-go discriminations employing on-key stimuli. Rilling, Askew, Ahlskog, and Kramer (1969) trained pigeons on a VI-EXT discrimination and its reversal; the response was keypecking and the discriminative stimuli (red and green) were projected on the key. The pigeons were provided with a second response key (white); for one group of birds, a single peck to this key switched off the discriminative stimulus and the chamber's houselight for $30 \mathrm{sec}$, while for another group pecks to the white key had no consequence. Early in discrimination training, both groups responded to the white (time-out) key during $S_{-}$, but the responding disappeared after two sessions in the group for which such responses had no effect while it remained high in the group which could escape $\mathrm{S}_{-}$. Following reversal of the discriminative stimuli, time-out responding declined considerably. In both phases of discrimination training, time-out responses, when they occurred, occurred early in the 4-min S- stimulus components. Time-out responding from $\mathrm{S}+$ was virtually nonexistent. Although they eliminated several alternatives to the escape from S- account of their data, Rilling et al. (1969) pointed out that positive reinforcement by stimulus change rather than negative reinforcement by termination of $\mathrm{S}-$ could not be ruled out.

Terrace (1971) included conditions to control for displaced pecking and stimulus change. He trained pigeons in a VI-EXT discrimination using on-key line stimuli; Groups I, II, and III learned "with errors" and Group IV was trained "without errors" (by gradually fading in S-). Pecks to a second, white key on the left turned off $\mathrm{S}-$ on the center operant key for $5 \mathrm{sec}$ for Groups I and IV; they had no effect for Group II (a "displacement" control) and changed the left key from white to black for $5 \mathrm{sec}$ for Group III (a "stimulus change" control). During discrimination learning, only Group I responded to the left key at a substantial rate. Terrace concluded that left-key responses were reinforced by escape from an aversive S- in Group I. Since Groups II and III made few left-key responses, Terrace rejected the possibility that left-key responding represented displaced pecking during S- or was reinforced by stimulus change alone. The absence of escape responding in Group IV was evidence that extinction-produced increases in activity did not explain the escape responding in Group I.

While the experiments to be reported here were generated by the hypothesis that $\mathrm{S}-$, as a signal for nonreward, is aversive, the limitations of the experiments described above as evidence for $\mathrm{S}-$ aversiveness must be appreciated. The criterion that termination of $\mathrm{S}-$ reinforces some "new" response in order to be considered a conditioned negative reinforcer is not really met in the work of Rilling et al. (1969) or Terrace (1971, 1972), since the time-out, or escape, response for the pigeons was pecking a second key after they had already learned to peck a nearby key for food reinforcers; pecking a key in one location may be a different response from pecking another key, but it is far from clear that it is a new response. Also, the frequency of responses to produce time-out is not particularly high. Though the data are not given, it is possible from Terrace's (1971) verbal description of the results to compute the mean percent of total S- time escaped; for Session 1, only $5 \%$ of $\mathrm{S}-$ was escaped, and for Sessions $11-14$, only about $4 \%$ of the S- time was escaped!

Coughlin (1972) has questioned whether it is the aversiveness of $\mathrm{S}-$ that supports time-out responding. Coughlin (1970; cited in Coughlin, 1972, 1973) was unable to replicate the findings of Rilling et al. (1969) when the effects of stimulus change were controlled. Coughlin (1972) found that the addition of electric shock punishment for operant-key responding during $\mathrm{S}-$, a procedure one would expect to increase the aversiveness of $\mathrm{S}-$, actually decreased the rate of responding on the time-out key. Furthermore, substantial rates of time-out responding were maintained only when such responding produced total chamber blackout as well as removal of the EXT stimulus from the operant key. The first result is consistent with the earlier suggestion that time-out keypecking is not entirely different from operant keypecking; suppression of operant keypecking by punishment generalized to time-out keypecking. The second result might be explained by assuming that blacking out the chamber plus the EXT stimulus represents a more thorough escape from the stimuli associated with nonreward than does elimination of only the EXT stimulus. Coughlin, however, interpreted the result as support for the proposition that the reinforcer for time-out responding is stimulus change (see, also, McCall, 1965).

While these criticisms indicate that $\mathrm{S}$ - may be less aversive than first supposed, it remains clear that rats and pigeons will engage in behavior that removes $\mathrm{S}$-. Both Coughlin (1973) and Terrace (1972) noted that a frequent behavior of their birds during $S$ - was turning away from the key on which $S$ - was displayed; Coughlin pointed out that this behavior is sufficient to escape from $\mathrm{S}_{-}$, which may explain the low rates of time-out keypecking. Such behavior will also result in enhanced discriminative performance, as measured by the discrimination ratio.

\section{EXPERIMENT 1}

Experiment 1 was intended to test the hypothesis that auditory stimuli fail to produce good discriminative performance because the signal for extinction ( $\mathrm{S}-$ ) 
is not escapable by means of a response incompatible with keypecking. If this is the case, performance should be improved in a group provided with such a response.

Two groups of pigeons were trained in a variable. interval extinction discrimination employing tones, differing in frequency and intensity, as $\mathrm{S}^{+}$and $\mathrm{S}-$; the grain-rewarded response was pecking a continuously lit green key. One group of pigeons could escape into silence by going to the rear half of the chamber, a response that precluded pecking the key; the second group experienced continuous, uncontrollable tones. It was expected that the first group would learn to escape $S_{-}$, reducing the number of keypecks during $S_{-}$and thereby producing better discriminative performance.

\section{Method}

Subjects. The subjects were 16 experimentally naive domestic pigeons obtained from a local supplier and maintained at $75 \%$ of their free-feeding weights throughout the experiment. The birds were housed individually in a colony with a 16-h-light/8-h-dark cycle. They had continuous access to grit and water. Supplemental feeding was given in the home cage only when an experimental session was not scheduled for the following day. The subjects were assigned randomly to treatment groups of equal size.

Apparatus. Training was conducted in two similarly modified Grason-Stadler pigeon Skinner boxes. The bird's chamber was $28.6 \mathrm{~cm}$ long $\times 28.6 \mathrm{~cm}$ wide $\times 24.1 \mathrm{~cm}$ high. The wire-mesh tilt floor, which operated a microswitch that determined the pigeon's location in the front or rear of the chamber, pivoted $15.2 \mathrm{~cm}$ from the intelligence panel. The floor moved $.4 \mathrm{~cm}$ at the ends, the equivalent of $1.6 \mathrm{deg}$ rotation about its axle. The hopper aperture, $3.8 \mathrm{~cm}$ high $\times 5.1 \mathrm{~cm}$ wide, was located on the midline of the intelligence panel $7.6 \mathrm{~cm}$ above the floor. The pecking key, which required $12 \mathrm{~g}$ force $(.12 \mathrm{~N})$ to operate, was $1.9 \mathrm{~cm}$ in diameter and located $19.0 \mathrm{~cm}$ above the floor (11.4 cm above the hopper). The chamber was illuminated by a No. 1829 lamp (operated at $24 \mathrm{~V} \mathrm{dc}$ ) mounted behind a $3.8-\mathrm{cm}$ diam porthole in the extreme upper right-hand corner of the intelligence panel. The background noise level, produced by the ventilating fan, was $80 \mathrm{~dB}$ (re $.0002 \mathrm{dynes} / \mathrm{cm}^{2}$ on the "A" scale).

The 555-nm (peak wavelength) key stimulus was produced by a No. 1815 lamp (operated at $12.5 \mathrm{~V} \mathrm{dc}$ ) in an IEE projector (Model 00010-01-3043-1815) equipped with a KodakWratten filter No. 99 . The $2.5-\mathrm{cm}$-diam projection surface was $.6 \mathrm{~cm}$ behind the clear plastic paddle of the pecking key. The two tone stimuli were produced by a pair of Mallory Sonalerts mounted side by side in a small Plexiglas enclosure, with the bottom open, attached to the ceiling at the rear of the chamber: $\mathrm{S}+$ (Model SC628H) was $4,500 \mathrm{~Hz}$ at $102 \mathrm{~dB} ; \mathrm{S}$ - (Model SC628) was $2,800 \mathrm{~Hz}$ at $87 \mathrm{~dB}$. Sound pressure levels (re .0002 dynes/ $\mathrm{cm}^{2}$, "A" scale) were measured at the center of the chamber with the microphone perpendicular to a line from the Sonalerts to the key; frequency is reported according to the manufacturer's specifications. The presentation of stimuli, delivery of reinforcement, and recording of data were performed by conventional electromechanical programming equipment.

Procedure. Each bird was magazine trained to approach and eat from the elevated, lighted hopper and hand-shaped to peck the lit key in the presence of the S+ tone. In the same session, the pigeon earned 20 reinforcers (consisting of 3 -sec access to a mixture of milo, kafir, and wheat) on a continuous reinforcement (CRF) schedule, followed by 40 reinforcers on a preprogrammed schedule in which the density of reward was gradually changed from CRF to variable interval (VI) $30 \mathrm{sec}$, followed by
40 reinforcers on a rectangularly distributed VI $30-\mathrm{sec}$ schedule with minimum and maximum intervals of 5 and $55 \mathrm{sec}$, respectively. In the second and third pretraining sessions, the pigeons were given $30 \mathrm{~min}$ of single-stimulus (SS) training on the same VI $30-\mathrm{sec}$ schedule in the presence of the $555-\mathrm{nm}$ key stimulus and the $\mathrm{S}+$ tone.

Session 1 of discrimination training began on the 4 th day. Each of the $20 \frac{1}{2}-\mathrm{h}$ discrimination training sessions consisted of 151 -min S+ components (VI $30 \mathrm{sec}$ ) and 151 -min S-components (extinction, or EXT) presented in one of four quasirandom sequences with the censtraint that no more than three components in a row be the same; stimulus components were not separated by blackouts. At the end of the session, the houselight, key light, and discriminative stimuli were switched off

One group, designated $\mathrm{CT} \pm$ (for "control tones, positive and negative"), could switch off the discriminative stimuli by moving beyond the tilt-floor pivot toward the rear of the chamber; observation indicated that from that distance the birds could not peck the key. Moving to the rear of the box had no consequence other than a switch to silence; the present schedule of reinforcement, the duration of the stimulus component, and the sequence of stimuli were unaffected by the bird's location. The second group, designated ST (for "steady tones"), could not switch off either the $S+$ or the $S$ - tones.

The data collected were total keypecks during $\mathrm{S}+$, total keypecks during $\mathrm{S}_{-}$, time at the rear of the box during $\mathrm{S}^{+}$, time at the rear of the box during $\mathrm{S}-$, the total number of times $\mathrm{S}+$ was switched off (i.e., crossings in $\mathrm{S}+$ ), and the total number of times S- was switched off (i.e., crossings in S-). Time-out of $\mathrm{S}+$ and time-out of $\mathrm{S}$ - were sampled on alternate sessions.

\section{Results and Discussion}

Figure 1 presents the mean percent of total keypecks to $\mathrm{S}+$ (the discrimination ratio) as a function of sessions for both groups. Group CT \pm and Group ST had discrimination ratios of $50 \%$ and $51 \%$, respectively, on Day 1 and ratios of $78 \%$ and $61 \%$, respectively, on Day 20. Both groups improved comparably for the first four sessions, after which very little change in the performance of Group ST was seen while Group CT \pm continued to improve throughout the 20 days of discrimination training. A two-way analysis of variance with one repeated measure revealed that the two groups differed reliably $[F(1,14)=9.09, p<.01]$, that there

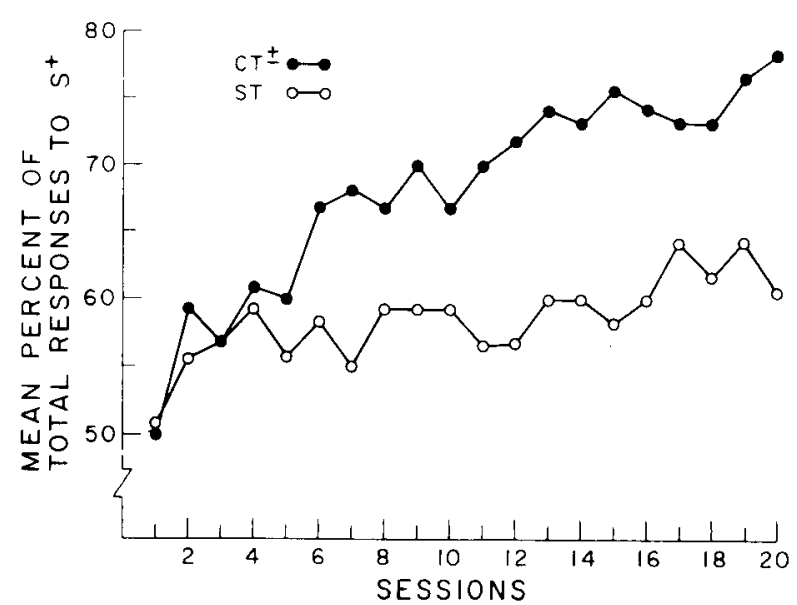

Figure 1. Mean discrimination ratios for 20 sessions for Groups C $T \pm$ and $S T$ in Experiment 1. 


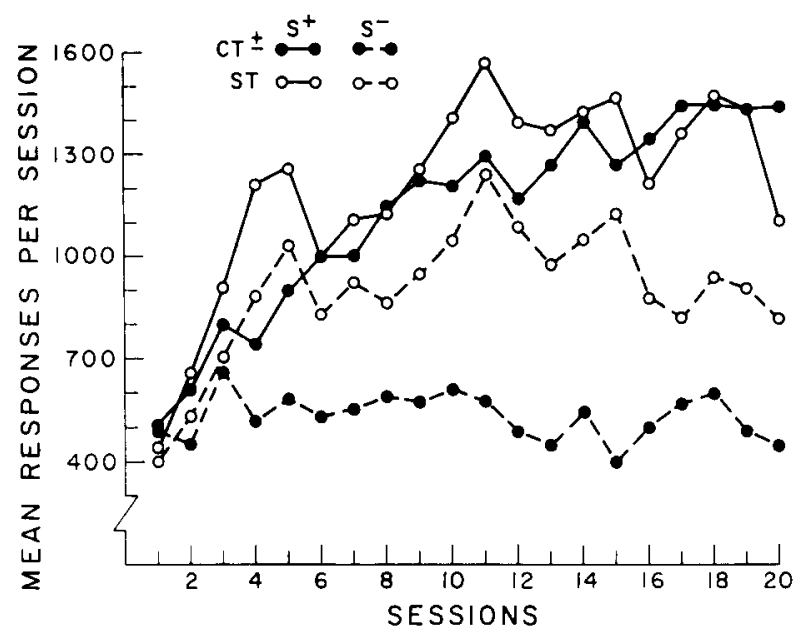

Figure 2. Mean keypecks per session during $S+$ and $S-$ for Groups $\mathrm{CT} \pm$ and $S T$ in Experiment 1.

was a reliable effect of sessions $[F(19,266)=9.24$, $\mathrm{p}<.001]$, and that treatments (groups) interacted reliably with sessions $[\mathrm{F}(19,266)=2.96, \mathrm{p}<.001]$.

The mean number of keypecks per session during $\mathrm{S}+$ and $\mathrm{S}-$ for 20 days of discrimination training are shown in Figure 2. It is clear that the superior discriminative performance by subjects in Group CT \pm is largely due to the fact that they had lower rates of responding during S- than did subjects in Group ST; while Srates remain at their initial level throughout discrimination training in Group CT \pm , they increase steadily for the first 11 sessions before declining slightly in Group ST. A two-way analysis of variance with one repeated measure of responses during $\mathrm{S}$ - produced a reliable effect of groups $[F(1,14)=6.66, p<.05]$, a reliable effect of sessions $[F(19,266)=2.58, p<.001]$, and a reliable Group by Sessions interaction $[F(19,266)=$ $2.32, \mathrm{p}<.005]$.

There was very little difference between the two groups in keypecking during $\mathrm{S}+$, although subjects in Group CT \pm achieved asymptotic S+ rates earlier in training than did subjects in Group ST. A two-way analysis of variance with one repeated measure applied to S+ responding revealed a reliable effect of sessions $[F(19,266)=14.97, p<.001]$ and a reliable interaction between groups and sessions $[F(19,266)=1.95$, $p<.05]$; the main effect of groups was not significant $(\mathrm{F}<1)$.

The expectation that providing subjects with a means of escaping $\mathrm{S}-$ via a response incompatible with keypecking would reduce $S$ - keypecking rates and produce better discriminative performance was fulfilled. To determine whether reduced $\mathrm{S}$ - responding was mediated by escape from $S-$, it is necessary to compare escapes from S+ and S- (crossings) and times out of S+ and Sfor the subjects of the group that could switch off the discriminative stimuli with the analogous measures for the subjects of the group which could not. Because times out of the two stimuli were collected on alternate days, the data that follow are actually based on means per session for each subject for five blocks of four sessions each. Accordingly, the independent variable called "sessions" above will be called "blocks" below.

Figure 3 shows the mean number of times per session that subjects in each group crossed to the rear of the box during $\mathrm{S}+$ and during $\mathrm{S}-$ as a function of five blocks of four sessions each. It can be seen that crossings to the rear of the chamber were more frequent during $S-$ than during $S+$ for both groups and that the frequency neither steadily increased nor decreased over blocks of sessions for either group during either stimulus. A three-way analysis of variance with two repeated measures, employing groups, blocks, and stimuli as factors, revealed that the sole reliable effect was for stimuli, S+ vs. $S-[F(1,14)=15.44, p<.005]$.

Figure 4 shows the mean time per session spent out of $\mathrm{S}+$ and $\mathrm{S}-$ for Group $\mathrm{CT} \pm$; the corresponding time at the rear of the box during St and S- for Group ST is also presented. Recall that each session contained up to $900 \mathrm{sec}$ of St and up to $900 \mathrm{sec}$ of S-; Group CT \pm "escaped" less than 3.3\% of S- time. (The large amount of time-out of $\mathrm{S}+$ in the first block of sessions for Group $\mathrm{CT} \pm$ is due to the fact that the first two sessions began with $\mathrm{S}+$ components; several $\mathrm{CT} \pm$ pigeons "stood out" the first few minutes of the first few sessions, depriving themselves mostly of S+ exposure.) Disregarding the first block of four sessions, it can be seen that more time is spent in the rear of the chamber during $\mathrm{S}-$ than during S+ but that the two times converge at the fifth block. An analysis of variance of the same design employed in examining the crossings data was applied to the last four blocks of the time-in-rear data. There was a reliable main effect of stimuli, S+ vs. S$[F(1,14)=17.79, p<.005]$ and a reliable Stimuli by Blocks interaction $[F(3,42)=3.14, p<.05]$.

Thus, both measures of escape (crossings and timeout) in Group CT \pm did not differ from the identical behaviors (which were without consequence) in

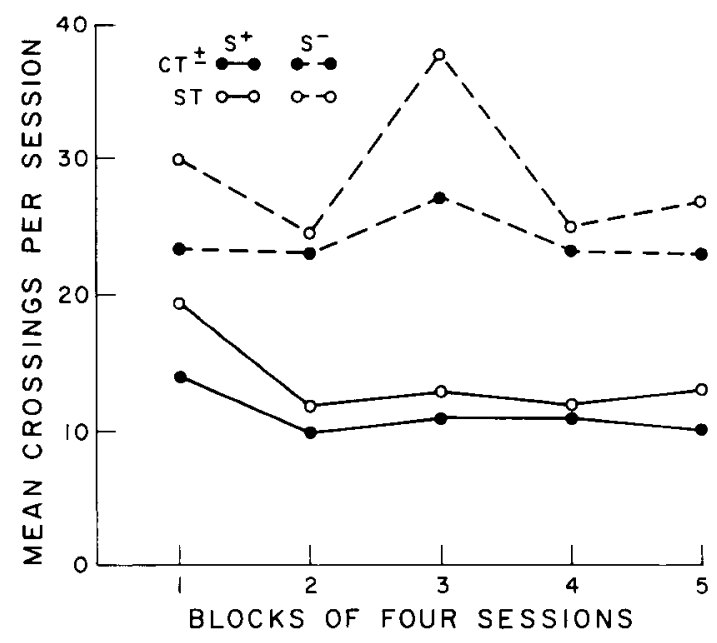

Figure 3. Mean crossings per session during $S+$ and $S-$ by blocks of four sessions for Groups $\mathrm{CT} \pm$ and $\mathrm{ST}$ in Experiment 1. 


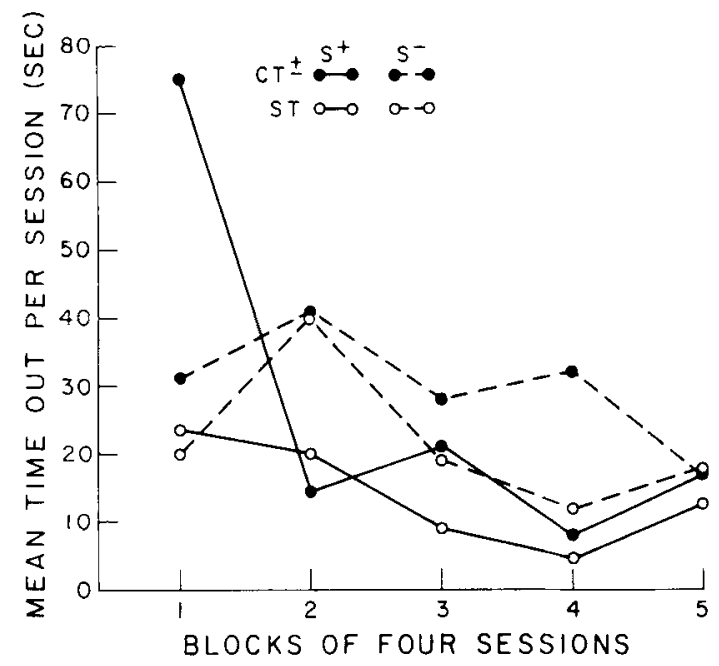

Figure 4. Mean time in the rear of the chamber during $S+$ and $S$ - per session by blocks of four sessions for Groups CT \pm and $S T$ in Experiment 1.

Group ST. In this context, Group ST might be regarded as a "displacement" control (Terrace, 1971); the present findings indicate that, during $\mathrm{S}-$, subjects are more active and wander around the box. Note that the typical "escape" response has a duration of less than $1 \mathrm{sec}$, which is much more consistent with a bird's momentarily leaving the region of the intelligence panel than with a purposive movement to the rear of the chamber in order to escape an aversive $\mathbf{S}-$.

The data are consistent with the conclusion that subjects are more active and that the activity is more variable during periods of nonreward. The data are not consistent with any proposition, including the escape hypothesis, based on the aversiveness of $\mathrm{S}-$, since, presumably, $\mathrm{S}$ - would acquire aversiveness as a function of learning, which, in turn, depends on experience. The frequency of crossing (Figure 3) should change systematically over sessions; it does not.

The strong hypothesis tested in Experiment 1 explicitly proposes that response rates to $\mathrm{S}-$ in Group CT \pm should be reduced in proportion to the time spent out of S-. That is to say, in terms of discriminative performance, a discrimination ratio based on total responses per session during $S+$ and $S$ - should reveal good performance, but a discrimination ratio based on response rates in the presence of $\mathrm{S}+$ and $\mathrm{S}-$ (where the denominator for rate is the actual time the stimulus was on) should reveal poor performance, comparable to that seen in Group ST. The standard ratio (Figure 1) is simply total responses to $\mathrm{S}+$ divided by total responses to $\mathrm{S}+$ and $S-$; the time-corrected ratio is response rate in the presence of $S+$ divided by the sum of the response rates in St and $\mathrm{S}$ - (i.e., corrected for the time spent in silence). The mean standard discrimination ratio and the mean time-corrected discrimination ratio (expressed as percentages) for Group $\mathrm{CT} \pm$ for Blocks 1 through 5 were: (1) $55.7 \%$ and $57.1 \%,(2) 65.2 \%$ and $64.5 \%$,
(3) $68.8 \%$ and $68.7 \%,(4) 74.0 \%$ and $73.5 \%$, and (5) $74.8 \%$ and $74.7 \%$. As one would expect, given the small amount of time in silence, the "correction" procedure had almost no effect. A Ratio Type by Blocks (both repeated measures) analysis of variance revealed no effect of ratio type $(F<1)$, an effect of blocks (learning curve) $[F(4,28)=11.21, p<.001]$, and a Ratio Type by Blocks interaction $[F(4,28)=3.19, p<.05]$, reflecting the intertwining of the two ratio types.

To summarize, when pigeons can terminate the discriminative stimuli of a go/no-go (VI-EXT) discrimination via a behavior incompatible with keypecking, they perform the discrimination better than they can when they cannot control the discriminative stimuli. However, the superior performance is not due to prolonged escape from $\mathrm{S}$ - or even frequent movement away from the pecking key. The present data challenge the proposition that termination of an aversive $\mathrm{S}$ - will negatively reinforce a new (not previously learned) behavior. They do indicate that during periods of nonreward, hungry pigeons engage in more gross motor activity (locomotion) than during periods when a localized response, such as pecking a key, is rewarded.

\section{EXPERIMENT 2}

In Experiment 1 it was found that a procedure that endowed diffuse auditory discriminative stimuli with some of the functional properties of localized visual (on the key) discriminative stimuli enhanced discriminative performance. Although the superior performance of the group that could escape the discriminative stimuli by means of a response incompatible with the measured operant, keypecking, was not the result of escaping from S--, it may still have been the result of the escapability of S-. At the same time, the escapability of S+ may have played a role as well. To investigate this possibility, in Experiment 2 there were four treatment groups: (1) Group CT \pm (for "control tones positive and negative") could control (escape) S+ and S-, (2) Group CT+ (for "control positive tone") could control only St, (3) Group CT- (for "control negative tone") could control only S-, and (4) Group ST (for "steady tones") could not control either $\mathrm{S}+$ or $\mathrm{S}-$.

\section{Method}

Subjects. The subjects were 32 experimentally naive domestic pigeons obtained from a local supplier and maintained as in Experiment 1 . They were assigned randomly to four groups of eight subjects each.

Apparatus. The same pigeon chambers and electromechanical control and recording equipment employed in Experiment 1 were used in the present experiment.

Procedure. Keypeck training and single-stimulus pretraining were conducted in the same manner as in Experiment 1. Session 1 of discrimination training began on the 4th day; the same key stimulus, auditory discriminative stimuli, schedules of reinforcement, and sequences of stimuli were employed. Subjects in Group CT \pm could switch off the $\mathrm{S}+$ tone or the $\mathrm{S}$ - tone 
(producing silence) by crossing the pivot point of the tilt floor to the rear of the chamber. Subjects in Group ST could not terminate either S+ or S-. (Note that Groups $\mathrm{CT} \pm$ and $\mathrm{ST}$ of the present experiment were treated identically to the two groups of the same designations in Experiment 1.) Subjects in Group CT+ could switch off the S+ tone by crossing to the back of the chamber; the $S$ - tone was presented at its prescheduled time regardless of the bird's position in the chamber. Subjects in Group CT - could switch off the $S$ - tone by entering the rear half of the chamber; the $S+$ tone was presented at its prescheduled time regardless of the pigeon's location.

\section{RESULTS AND DISCUSSION}

Figure 5 presents the mean percent of total responses to St (the standard discrimination ratio of Experiment 1) for four groups as a function of 20 sessions of discrimination training. As in Experiment 1, the discriminative performances of the groups begin to diverge on Day 6; while performance continued to improve steadily in Groups $\mathrm{CT} \pm$, $\mathrm{CT}+$, and $\mathrm{CT}-$, very little change is seen in Group ST beyond the sixth session. The finding from Experiment 1 that the subjects that could control the presence of both discriminative stimuli (Group CT \pm ) achieve better discriminative performance than the subjects without control (Group ST) was replicated. More significantly, the subjects that could control the presence of only one of the discriminative stimuli, regardless of whether the stimulus was $\mathrm{S}+$ or $\mathrm{S}-$, performed the discrimination comparably to the birds able to control both discriminative stimuli. The discrimination ratios of the last 10 days of discrimination training (Sessions 11-20), the period during which differences among groups had clearly begun to emerge, were subjected to a two-way analysis of variance with one repeated measure, employing treatments (groups) and sessions as independent variables. The main effect of sessions was reliable $[F(9,252)=2.65, p<.01]$; the Treatments by Sessions interaction was not reliable $[\mathrm{F}(27,252)=1.3443, \mathrm{p}>.12]$. Planned orthogonal comparisons between groups revealed that: (1) the

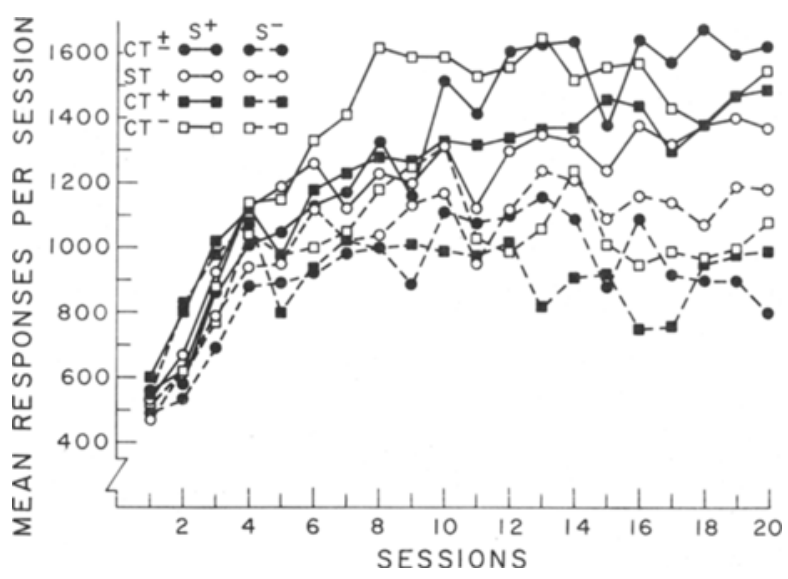

Figure 5. Mean discrimination ratios for 20 sessions for Groups CT, $\pm C T+, C T-$, and ST in Experiment 2.

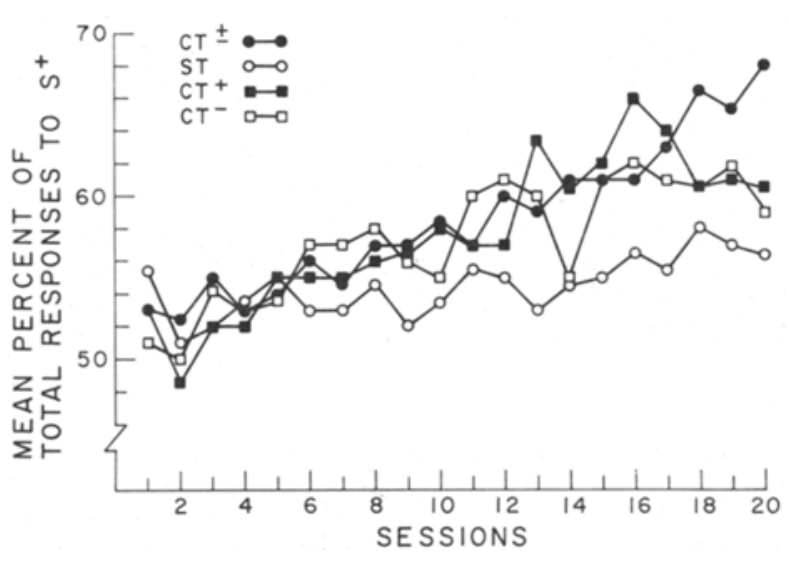

Figure 6. Mean keypecks per session during $S+$ and $S-$ for Groups $\mathrm{CT} \pm, \mathrm{CT}+, \mathrm{CT}-$, and $\mathrm{ST}$ in Experiment 2.

three groups with control of one or both stimuli (CT \pm , $\mathrm{CT}+$, and $\mathrm{CT}-$ ) differed reliably from the group with no control (ST) $[F(1,28)=4.40, p<.05] ;(2)$ the group with control of both stimuli (CT \pm ) did not differ reliably from the groups with control of only one (CT+ and $\mathrm{CT}-)(\mathrm{F}<1)$; and (3) the group with control of $\mathrm{S}+$ $(\mathrm{CT}+)$ did not differ reliably from the group with control of $\mathrm{S}-(\mathrm{CT}-)(\mathrm{F}<1)$. The mean discrimination ratios over Sessions 11-20 of Groups CT,$\pm \mathrm{CT}+, \mathrm{CT}-$, and ST were $62.3 \%, 61.3 \%, 60.1 \%$, and $55.5 \%$, respectively.

Figure 6 shows mean keypecks per session during St and during $S$-- for four groups over the course of 20 discrimination training sessions. It can be seen that the between-groups differences in discriminative performance were as much the result of differences among groups in S+ responding as the result of differences in S- responding. For example, subjects in Group ST, which had the lowest mean discrimination ratio of the four groups, had both consistently low St response rates and high $\mathrm{S}-$ response rates.

Groups by Sessions two-way analyses of variance with one repeated measure were separately applied to keypecks per session during $\mathrm{S}+$ and during $\mathrm{S}$ - over the last 10 days of discrimination training (Sessions 11-20), the same period for which discrimination ratios were analyzed. For $\mathrm{S}$ - responding, no main effects or interactions were statistically reliable. The planned orthogonal comparisons applied to the discrimination ratios above were not performed, since $p\left(F_{\max }\right)>.28$. For $\mathrm{S}+$ responding, only the main effect of sessions was reliable $[F(9,252)=2.36, p<.05]$. As with $S$-responding, the planned orthogonal between-groups comparisons of $S$ responding were foregone, since $\mathrm{p}\left(\mathrm{F}_{\mathrm{max}}\right)>.19$.

As in Experiment 1, mean crossings to the rear of the chamber per session, averaged across four-session blocks, were subjected to a three-way analysis of variance with two repeated measures. The factors were blocks (5), stimuli (S+ vs. S-), and groups. Crossings to the rear 
during $S-($ mean $=19.5$ per session $)$ were much more frequent than during $\mathrm{St}$ (mean $=4.0$ per session) $[F(1,28)=34.46, p<.001]$. The rate of crossing during the two discriminative stimuli diverged over blocks of sessions (for the first block, S+ mean $=7.5$ crossings per sessions and $S-$ mean $=14.5$ crossings per session; for the fifth block, $S+$ mean $=2.1$ crossings per session and $S-$ mean $=18.2$ crossings per session $)[F(4,112)=$ $6.25, \mathrm{p}<.001]$; all other $\mathrm{ps}>.20$. The absence of a reliable groups main effect or interaction is consistent with the finding in Experiment 1 that, although groups differed in discriminative performances, they did not differ in making the nominal "escape" response.

Time in the rear of the chamber was not recorded daily as it had been in the first experiment. However, event records, which indicated the bird's location in the chamber and the stimulus present, were collected for several of the sessions. They revealed that most entries to the rear of the chamber were extremely brief (on the order of $1 \mathrm{sec}$ ) and that cumulative times in the rear per session were small for all subjects. As in Experiment 1, there were no apparent differences among groups (see also Footnote 1).

The present finding that the ability to escape S+ and the ability to escape $\mathrm{S}$ - equally facilitate the acquisition of an auditory discrimination seriously undermines the original hypothesis that the typically poor auditory stimulus control of keypecking is due to the pigeon's inability to escape, via a response incompatible with keypecking, an aversive auditory $\mathrm{S}-$. Coupled with the finding that control of both discriminative stimuli does not enhance discriminative performance more than control of only one of the discriminative stimuli, the results of Experiment 2 strongly suggest that the effect of control is not restricted to behavior in the presence of the controllable stimulus. ${ }^{1}$

\section{GENERAL DISCUSSION}

Auditory discriminative performance by pigeons is enhanced when one or both of the discriminative stimuli are endowed with some of the functional properties of on-key discriminative stimuli. In the case of on-key stimuli, the pigeon can "escape" the stimulus by closing its eyes or looking away, both of which preclude performance of the measured operant. In the present studies, the bird could switch off the auditory stimulus by moving to the rear of the chamber beyond "pecking range." Although discriminative performance is clearly affected by the escapability of the discriminative stimuli, it is equally clear that the improved discriminative performance is not the result of escape from the discriminative stimuli. Rather, it is some by-produce of the controllable stimuli that is responsible. Certainly the hypothesis that generated the experiments reported here-that is, that pigeons will escape an aversive $S$ - via a behavior which precludes keypecking and hence improve discrim- inative performance--was refuted. Indeed, the present data seriously challenge whether the $\mathrm{S}-$ of a go/no-go (VI-EXT) discrimination is, in fact, a conditioned negative reinforcer.

It should be noted that in both situations the stimulus experienced when the explicit discriminative stimuli are escaped is a Pavlovian inhibitory conditioned stimulus (CS-) in that food never occurs when the pigeon is looking away from the key or standing in silence at the rear of the chamber. It may be that positive transfer from the Pavlovian discrimination to the operant discrimination occurs.

In addition, the salience of the discriminative stimuli might be enhanced by the intermittency inherent in escapable (controllable) stimuli. If a stimulus captures attention at its onset, if attention to the stimulus diminishes as time since its onset elapses, and if the stimulus is available for association with reinforcers or with response-reinforcer contingencies only to the extent that the subject is attending to the stimulus, it follows that an intermittent stimulus, with its frequent onsets, should function better than a continuous stimulus as a discriminative stimulus. Such intermittency is a natural property of localized visual (on-key) stimuli; when auditory stimuli were made controllable in the present studies, such intermittency was a by-product. Since the auditory discriminative stimuli employed here were from the same continua, it is reasonable to speculate that the enhanced attentiveness to one stimulus, in the cases in which only St or only S- were controllable (Groups CT+ and CT- of Experiment 2), transferred to the other stimulus.

Another factor potentially contributing to attentiveness to the discriminative stimuli may have been that they were correlated with the subjects' behavior, an inherent property of controllable stimuli. If it is assumed, as above, that attention is a prerequisite for the formation of associations and that attention transfers to stimuli within the stimulus continuum, then discriminative performance should be enhanced when one or both of the discriminative stimuli are controllable.

It does not appear to be possible to design a readily interpretable experiment to distinguish between the effects of stimulus intermittency and correlation with behavior. Consider a yoking design in which a master subject controls tone onset and offset, as do CT \pm birds in the present experiments. For the yoked subject, tones would be intermittent but uncorrelated with behavior; however, unreinforced pecking in the absence of either tone could occur, making silence an operant $\mathrm{S}-$. For the master subject, however, silence is a Pavlovian $\mathrm{S}$-. The differences in the function of silence make the interpretation of any observed differences in the discriminative performance of master and yoked subjects problematic.

In conclusion, while it is clear that making normally uncontrollable discriminative stimuli controllable 
enhances discriminative performance, what property of controllable stimuli is responsible for the improvement or even how to identify that property remains unclear.

\section{REFERENCES}

Amsel. A. The role of frustrative nonreward in noncontinuous reward situations. Psychological Bulletin, 1958, 55, 102-119.

Amsel, A. Frustrative nonreward in partial reinforcement and discrimination learning. Psychological Review, 1962, 69, 306-328.

Covgullin, R. C. Escape from a stimulus correlated with nonreinforcement in a multiple schedule. Unpublished doctoral dissertation. University of Vermont, 1970.

Covghus, R. C. The aversive properties of withdrawing positive reinforcement: A review of the recent literature. Psychological Record, 1972, 22, 333-354.

Coughlin, R. C. Timeout from a stimulus correlated with the extinction component of a multiple schedule. Learning and Motivation. 1973, 4, 294-304.

Eск, K. O.. \& Thomas, D. R. Discrimination learning as a function of prior discrimination and nondifferential training: A replication. Journal of Experimental Psychology, 1970, 83, 511-513.

Eck, K. O., Noel, R. C., \& Thomas, D. R. Discrimination learning as a function of prior discrimination and nondifferential training. Journal of Experimental Psychology, 1969, 82, 156-162.

MCCALL, R. B. Stimulus change in light-contingent bar pressing. Journal of Comparative and Physiological Psychology, 1965 , 59. 258-262.

Powell, R. W. Effects of stimulus control and deprivation upon discriminative responding. Journal of the Experimental Analvsis of Behavior, 1973, 19, 351-360.
Rilling, M., Askew, H. R., Ahlskog. J. E., \& Kramer, T. J. Aversive properties of the negative stimulus in a successive discrimination. Journal of the Experimental Analysis of Behavior, 1969, 12, 917-932.

Terrace, H. S. Escape from S-. Learning and Motivation, $1971,2,148-163$.

Terrace, H. S. By-products of discrimination learning. In G. H. Bower (Ed.). The psychology of learning and motivation (Vol. 5). New York: Academic Press, 1972.

Wagner, A. R. Conditioned frustration as a learned drive. Journal of E:perimental Psychology, 1963, 66, 142-148.

\section{NOTE}

1. To test the possibility that discriminative performance in Groups CT + and CT-, which could control only one of the two discriminative stimuli, was based on which stimulus was controllable rather than on the stimuli per se, the controllability of the stimuli was reversed on the 25 th session. No disruption of discriminative performance was observed. For these two groups, the discrimination ratios of the last session of the original conditions and those of the first session for which conditions were reversed were compared in a two-way analysis of variance with one repeated measure, employing groups and conditions as independent variables. No main effects or interactions achieved statistical significance. In fact, all sources combined "explained" less than $9 \%$ of the variance. Thus, Groups CT+ and CT - were not discriminating between intermittent and steady tones, and it appears that the discriminations achieved by each of the four groups were based on the same properties of the discriminative stimuli.

(Received for publication November 1, 1979; revision accepted March 19, 1980.) 